\title{
Electromechanical and Dynamic Characterization of In-House-Fabricated Amplified Piezo Actuator
}

\author{
P. K. Panda, ${ }^{1}$ B. Sahoo, ${ }^{1}$ S. Raja, ${ }^{2}$ Vijaya Kumar M. P., ${ }^{2}$ and V. Shankar ${ }^{2}$ \\ ${ }^{1}$ Materials Science Division, National Aerospace Laboratories, Council of Scientific and Industrial Research, Bangalore 560017, India \\ ${ }^{2}$ Structural Technologies Division, National Aerospace Laboratories, Council of Scientific and Industrial Research, \\ Bangalore 560017, India
}

Correspondence should be addressed to P. K. Panda, pkpanda@nal.res.in

Received 21 November 2011; Accepted 27 December 2011

Academic Editor: Tao Li

Copyright () 2012 P. K. Panda et al. This is an open access article distributed under the Creative Commons Attribution License, which permits unrestricted use, distribution, and reproduction in any medium, provided the original work is properly cited.

A diamond-shaped amplified piezo actuator (APA) fabricated using six multilayered piezo stacks with maximum displacement of $173 \mu \mathrm{m}$ at $175 \mathrm{~V}$ and the amplification factor of 4.3. The dynamic characterization of the actuator was carried out at different frequencies $(100 \mathrm{~Hz}-1 \mathrm{kHz})$ and at different $\mathrm{AC}$ voltages $(20 \mathrm{~V}-40 \mathrm{~V})$. The actuator response over this frequency range was found neat, without attenuation of the signal. Numerical modeling of multilayered stack actuator was carried out using empirical equations, and the electromechanical analysis was carried out using ABAQUS software. The block force of the APA was $81 \mathrm{~N}$, calculated by electromechanical analysis. This is similar to that calculated by dynamic characterization method.

\section{Introduction}

Lead zirconate titanate (PZT) is a well-known piezo material that produces electric charges on application of mechanical stress (as sensor) or undergoes dimensional change when subjected to an electric field (as actuator) [1-5]. One major drawback of the piezo materials is the low displacement of the order of $0.1-0.15 \%$ of the total length; therefore, thick piezo stacks are required even for the moderate-strain requirements. For high-strain requirements wherein the requirement of the strain is in few millimeters, simple multilayer stacks are not suitable. This leads to the development of the various types of high-strain amplified actuators such as hydraulic actuator [6-13], Moonie [14] and Cymbal [15], diamond-shaped actuator, and bow-shaped actuator.

In this study, the details of the fabrication and characterization of a diamond-shaped amplified actuators rare presented. Numerical modeling of multilayered stack actuator and amplified actuator is carried out using empirical equations and the electromechanical analysis using ABAQUS software. The values are correlated to the experimental results.

\section{Experimental Procedure}

2.1. Preparation of PZT Slurry. PZT stacks were fabricated by tape-casting method using in-house-prepared PZT powders [16]. A well-dispersed PZT slurry was prepared using required amount of PZT powder, organic solvents (methyl ethyl ketone and ethanol), dispersant (Triton), binder, plasticizers, and so forth, by ball milling for $72 \mathrm{hr}$. An optimized PZT slurry composition is presented in Table 1. The slurry was then filtered and cast on a silicon-coated Mylar sheet using a laboratory tape caster. The thickness of the green tapes is varied between $20 \mu \mathrm{m}$ and $200 \mu \mathrm{m}$ by changing the parameters such as the clearance of doctor blade, the casting speed, and the viscosity of the slurry.

2.2. Fabrication of Multilayered (ML) Stack. The green PZT tapes of thickness $80 \mu \mathrm{m}$ were dried, cut into required dimensions, screen-printed with platinum electrode paste, and dried. The individual layers are then stacked and laminated one above the other using uniaxial stacking machine. Following the above procedure, 6 numbers of identical ML 


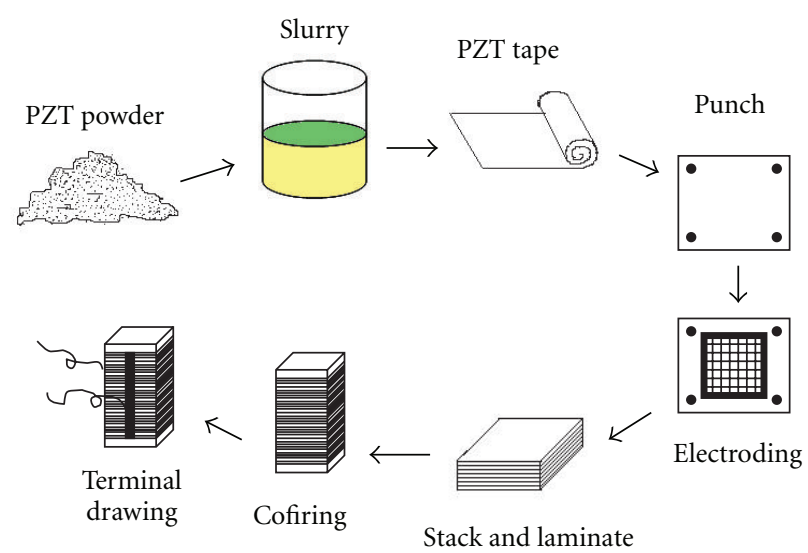

FIgURE 1: Pictorial representation of fabrication procedure of ML stack.
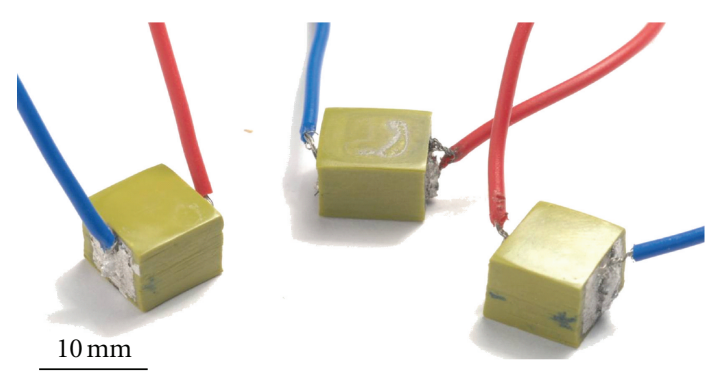

FIGURE 2: Typical picture of fabricated ML stacks.

TABle 1: Typical PZT slurry composition.

\begin{tabular}{lc}
\hline Components & Amounts (\%) \\
\hline PZT powder & $65-70$ \\
Dispersant & 1.25 \\
Solvent & 25 \\
Plasticizer & 1.75 \\
Binder & 2 \\
\hline
\end{tabular}

stacks of height $14 \mathrm{~mm}$ (green stage) are fabricated. All the stacks are then isopressed at $30 \mathrm{MPa} / 5 \mathrm{~min}$ with preheating at $60^{\circ} \mathrm{C} / 5 \mathrm{~min}$. Binder burnout of the stacks is carried out at $520^{\circ} \mathrm{C} / 2 \mathrm{~h}$ with very slow heating rate $\left(15^{\circ} \mathrm{C} / 1 \mathrm{~h}\right)$. The cofiring of the stacks is done at $1250^{\circ} \mathrm{C} / 1 \mathrm{~h}$. The stacks are leveled to have parallel surfaces, finished, and electrode, and two terminals are drawn by soldering the wires. A pictorial representation of fabrication procedure of ML stack is shown in Figure 1. The stacks are then poled at $2 \mathrm{kV} / \mathrm{mm}$ in hot silicone oil bath for $45 \mathrm{~min}$, and displacement and block force were characterized. Typical picture of the fabricated ML stack is shown in Figure 2.

2.3. Fabrication of Al Frame and APA. An aluminium metal frame of length $60 \mathrm{~mm}$ (internal) and height $24 \mathrm{~mm}$ (internal) is fabricated. The inside angle of the frame with its mid-

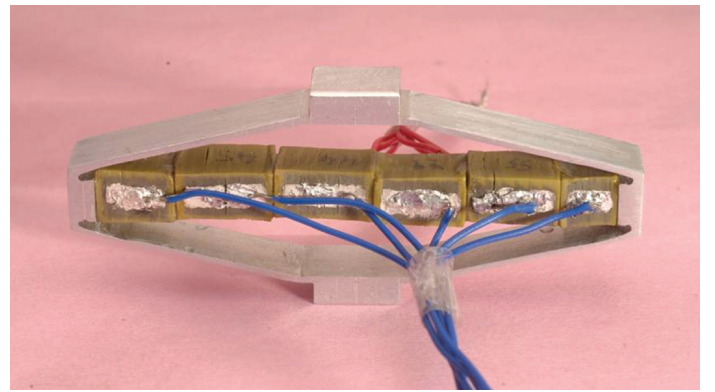

Figure 3: A typical picture of fabricated diamond-shaped APA.

dle horizontal line is $15^{\circ}$. All the $6 \mathrm{PZT}$ stacks are then fixed inside the metal frame using a flange in a prestressed condition. The photograph of fabricated diamond-shaped PZT actuator is shown in Figure 3. The weight of the APA is $26.5 \mathrm{~g}$.

\section{Results and Discussions}

3.1. Displacement and Block Force Measurement. The individual ML stacks are characterized for displacement and block force using a block force measuring unit. The actuator is placed on top of a force sensor (load cell) inside the sample holder, and its positive and negative terminals are properly connected to the respective terminals of the voltage 


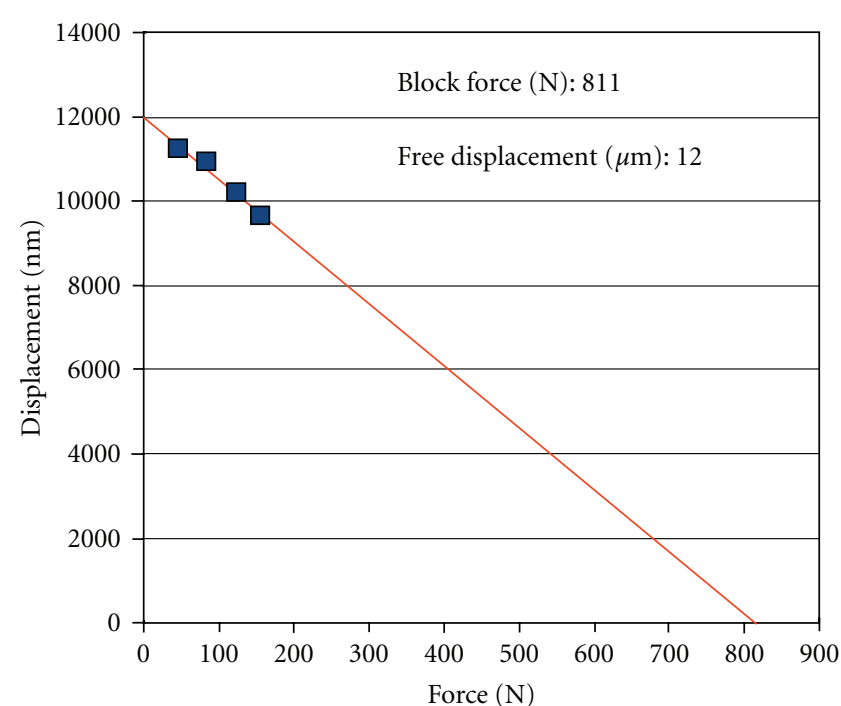

Figure 4: Block force versus free displacement graph of ML stack.

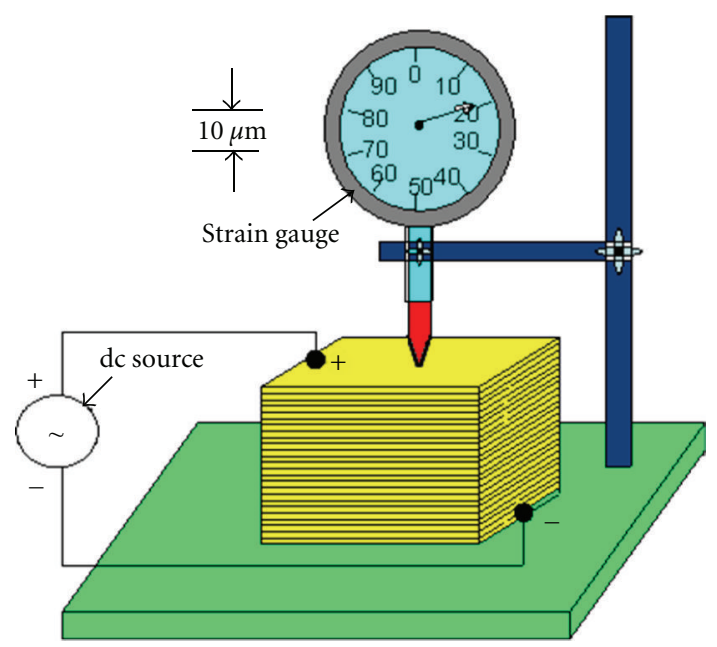

FIGURE 5: Test setup for displacement measurement of the actuators [16].

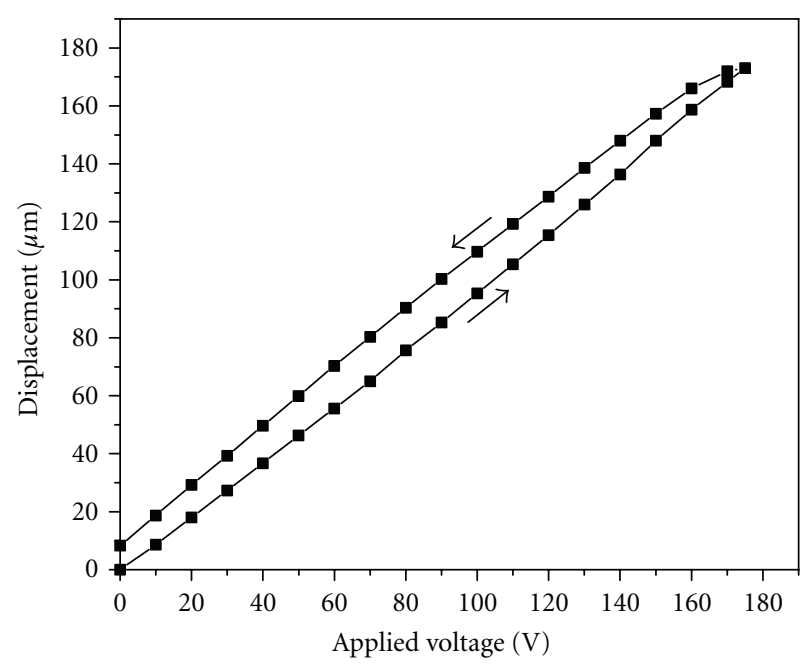

FIgURE 6: Displacement versus voltage graph of APA.

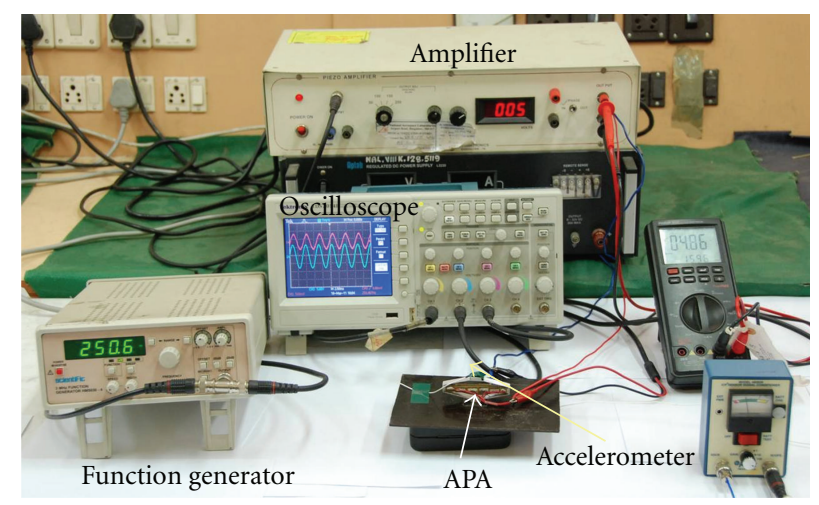

FIGURE 7: Test setup for voltage and frequency characterization of the APA.

source. Displacement of the actuator is measured by a highly sensitive laser interferometer. For measurement of block force, the actuator is prestressed by selecting a suitable spring of specific stiffness. The displacement and the force generated by the actuator for different springs are plotted. The software calculates a linear fit for these points. The block force is determined from the intersection points of the line on $X$-axis, and the free displacement is measured from its intersection on $Y$-axis. The graph of displacement versus force is shown in Figure 4.

The displacement characteristics of the APA and assembled ML stacks are measured using a strain gauge. The test setup for displacement measurement of the APA is shown in Figure 5. It is observed that the displacement increases with increase in voltage, and a maximum displacement of $173 \mu \mathrm{m}$ and $40 \mu \mathrm{m}$ is measured for APA and assembled ML stacks, respectively, at $175 \mathrm{~V}$. On decreasing the voltage, the displacement curve does not follow the same path and a hysteresis loop is obtained (Figure 6). The amplification factor for diamond-shaped APA is nearly 4.3 times.

3.2. Dynamic Characterization of Amplified Actuator. The piezo stack as an electrical load is capacitive in nature. The capacitance of the stack assembly is measured and is around $2.42 \mu \mathrm{F}$. This is a useful parameter in the design of electronics actuator amplifier for APA.

3.3. Characterization of the Actuator at Different AC Signal and Frequency. For vibration control applications, it is necessary to characterize the dynamic response of the stack at different amplified sinusoidal AC signal and at different frequencies. The dynamic response of APA was carried out at $40 \mathrm{~V}( \pm 20 \mathrm{~V})$ peak to peak and up to a frequency of $1 \mathrm{KHz}$. The test setup is shown in Figure 7. A sinusoidal input signal to the stack assembly produces mechanical vibrations on the stack which is coupled to a unit under test (UUT) either to carry out UUT's resonance search (open loop) or to control UUT's vibrations (closed loop). For dynamic applications, it is necessary to quantify the acceleration response on the stack assembly with respect to force input to the APA stack assembly at different input voltage levels as well as at different frequencies. A miniature accelerometer 


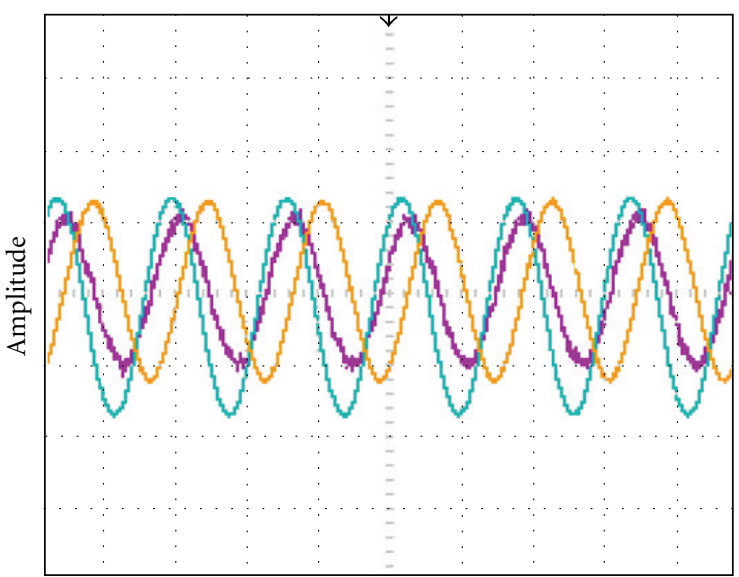

Time (ms)

(a) $250 \mathrm{~Hz}$ and $20 \mathrm{~V}$

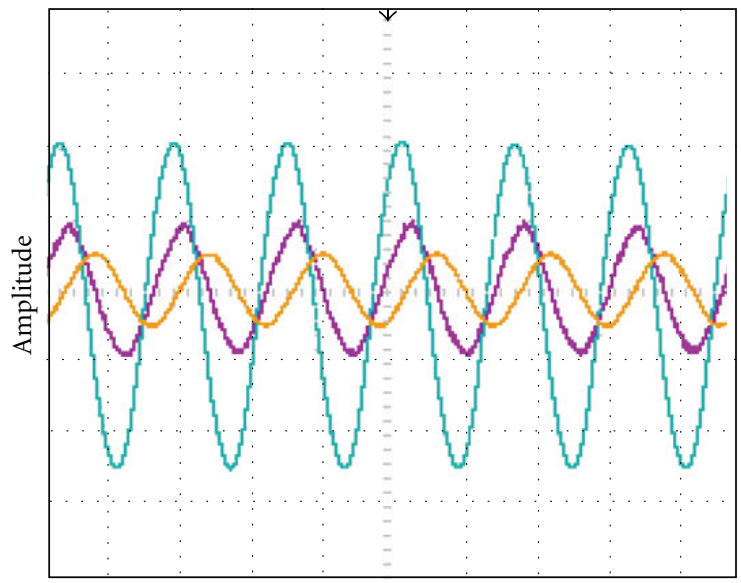

Time (ms)

(c) $250 \mathrm{~Hz}$ and $30 \mathrm{~V}$

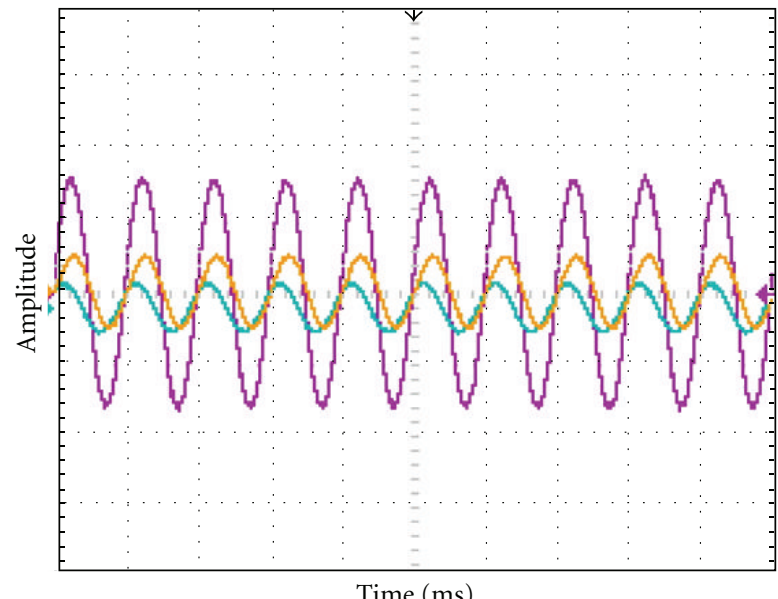

(b) $1000 \mathrm{~Hz}$ and $20 \mathrm{~V}$

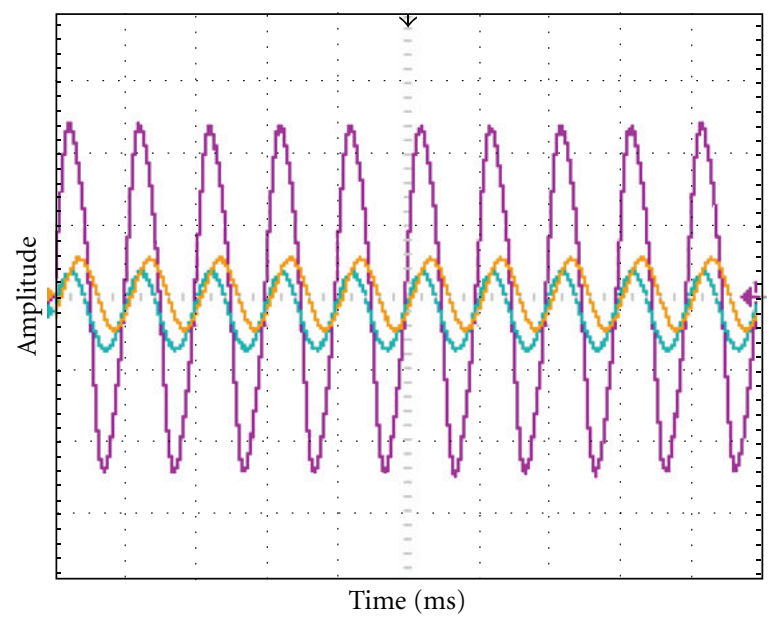

(d) $1000 \mathrm{~Hz} \& 30 \mathrm{~V}$

FIgURE 8: Typical plots of actuator response at (a) $250 \mathrm{~Hz}$ and $20 \mathrm{~V}$, (b) $1000 \mathrm{~Hz}$ and $20 \mathrm{~V}$, (c) $250 \mathrm{~Hz}$ and $30 \mathrm{~V}$, and (d) $1000 \mathrm{~Hz} \& 30 \mathrm{~V}$.

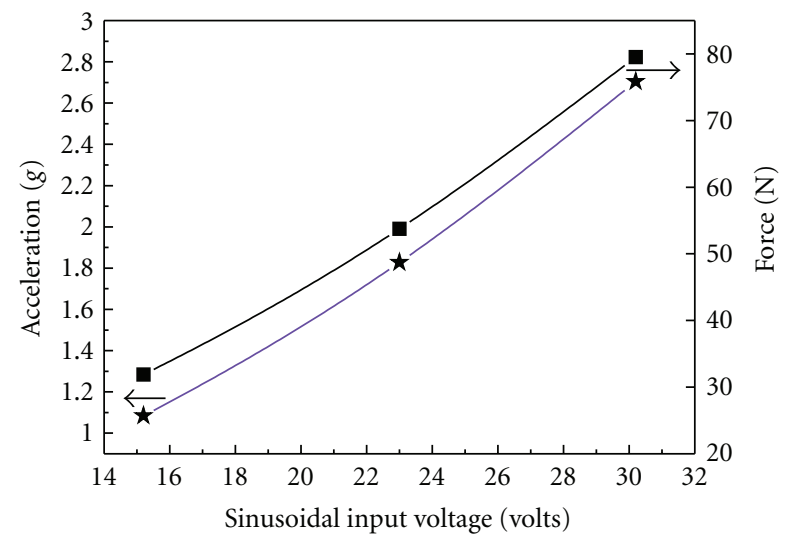

FIGURE 9: Variation of " $g$ " and actuator force versus input voltage.

(with $10.5 \mathrm{mV} / \mathrm{g}$ sensitivity and $0.2 \mathrm{~g}$ weight) was mounted on the stack followed by its signal conditioning amplifier.
The weight of the APA stack assembly is 26.5 grams. The total weight of the APA stack assembly and accelerometer together is 26.7 grams. Experiments were carried out and measurements were recorded on digital storage oscilloscope at three different sinusoidal input drive voltage levels ( $20 \mathrm{Vp}$ $\mathrm{p}, 30 \mathrm{~V} \mathrm{p}-\mathrm{p}$ and $40 \mathrm{~V} \mathrm{p}-\mathrm{p})$ to the stack actuator and in the frequency range of $125 \mathrm{~Hz}$ to $1 \mathrm{KHz}$. Typical plots of response of stack at $250 \mathrm{~Hz}$ and at $1000 \mathrm{~Hz}$ are presented in Figures $8(a)-8(d)$. From the sensitivity of the accelerometer and the mill volt output produced by the actuator, the acceleration $(g)$ and the force produced by the actuator were calculated. The " $g$ " was $2.7 \mathrm{~g} / \mathrm{cm}^{2}$, and the force was $81 \mathrm{~N}$ at 40 volts, and the variation at different voltage is presented in Figure 9.

3.4. Numerical Modeling of Multilayered Stack Actuator. The stack actuators are made up of thin layers of PZT patches, laminated one over the other. Modeling all the thin layers of PZT stack using the piezoelectric solid finite element, available in commercial software is cumbersome. Hence, 


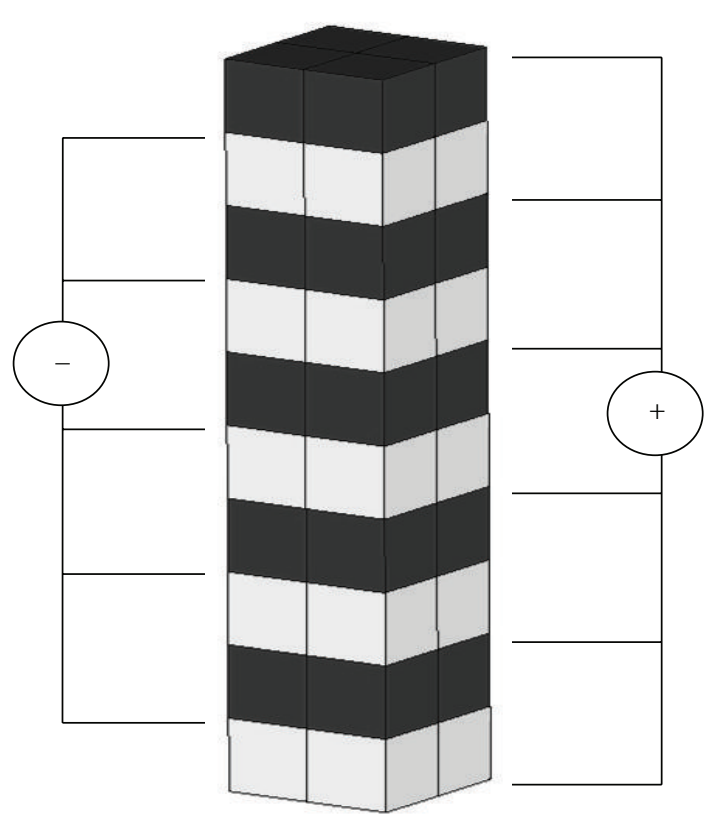

FIgURE 10: Finite-element model of the stack actuator.

TABLE 2: Actuator material properties.

\begin{tabular}{lcc}
\hline Properties & Data & units \\
\hline Young's modulus & 45 & $\mathrm{GPa}$ \\
Piezoelectric constant & $390 \times 10^{-12}$ & $\mathrm{~m} / \mathrm{v}$ \\
Density & 7500 & $\mathrm{~kg} / \mathrm{m}^{3}$ \\
Poisons ratio & 0.22 & - \\
\hline
\end{tabular}

an equivalent model is built from the following empirical relations:

$$
\begin{gathered}
\mathrm{D} x=n^{\prime} d_{33}^{\prime} \mathrm{EV}, \\
E_{33}=\frac{F_{\text {block }}^{\prime} t}{d_{33}^{\prime} A^{\prime} \mathrm{EV}}, \\
t=\frac{\text { length of the stack actuator }}{\text { number of layers in the actuator }}, \\
\phi_{\mathrm{fem}}=\frac{\text { voltage }_{\mathrm{cal}} \times \text { thickness }_{\mathrm{fem}}}{\text { thickness }_{\mathrm{cal}}},
\end{gathered}
$$

where $E_{33}$ is Young's modulus, $d_{33}$ represents piezoelectric strain constant, $n$ indicates the number of layers, EV refers to the electric potential across each layer, $A$ is cross-sectional area of the stack actuator, $t$ is thickness of each layer, $\phi_{\text {fem }}$ denotes equivalent electric potential in finite-element method.

3.5. Finite-Element Modeling of the Stack Actuator. Assuming 10 piezo layers, each of piezoelectric strain constant $(390 \times$ $10^{-12} \mathrm{C} / \mathrm{N}$ ), a finite-element model was created using square cross-section elements to avoid any discrepancy (Figure 10). The two consecutive layers of the finite-element model will have opposite polarity to each other, so as to obtain the extension/compression from all the layers simultaneously
TABLE 3: Characteristics of the actuator (actuator APA).

\begin{tabular}{lcc}
\hline Description & Data & Units \\
\hline Displacement & 41 & $\mu \mathrm{m}$ \\
Blocked force & 1450 & $\mathrm{~N}$ \\
Voltage range & 175 & $\mathrm{~V}$ \\
Height & 61.9 & $\mathrm{~mm}$ \\
Area & $8 \times 6$ & $\mathrm{~mm}^{2}$ \\
\hline
\end{tabular}

TABLE 4: Free deflection and block force of the stack actuator.

\begin{tabular}{lcc}
\hline Analysis & Displacement $(\mu \mathrm{m})$ & Blocked force $(\mathrm{N})$ \\
\hline APA & 41 & 1450 \\
FEA (ABAQUS) & 40.9 & 1452 \\
\hline
\end{tabular}

(i.e., parallel capacitor configuration). The actuator material properties used for modeling are presented in Table 2. Similarly, the characteristics of the actuator are presented in Table 3 .

The actuator is characterized using the stress-strain relation of a coupled electromechanical system

$$
\{s\}=[C]\{\varepsilon\}-[C][d]\left\{E_{k}\right\},
$$

where $C$ is the material stiffness matrices $\left(\mathrm{N} / \mathrm{m}^{2}\right), d$ is the piezoelectric strain constant $(\mathrm{m} / \mathrm{v}), E_{k}$ is the electric field $(\mathrm{v} / \mathrm{m})$, and $\varepsilon$ is the material strain.

3.6. Electromechanical Analysis Using ABAQUS. The free deflection and the block force are measured from the electromechanical analysis using ABAQUS. While the free deflection is the actuator deformation when maintained in an unconstrained state with the maximum applied voltage, the block force is the reaction developed by the actuator when maintained in a completely constrained state. The results of the analysis compared with the measured results are presented in Table 4, and the block force and free displacement profile are presented in Figures 11(a) and 11(b).

Figure 12 represents the CAD model of APA, in which the casing is made of aluminum material, and the actuator is placed in between the casing. The aluminum material properties used are Young's modulus $E=70 \mathrm{GPa}$, density = $2720 \mathrm{~kg} / \mathrm{m}^{3}$, and Poisson's ratio 0.3.

The weight of the APA is approximately 26.5 grams. Finite-element model of APA is made in Hypermesh and subsequently analyzed for static loading. Further the free vibration analysis is performed using ABAQUS. The static analysis has shown that the casing is safe with a factor of safety 4.7 .

3.7. Piezo Static and Electromechanical Analysis of the APA. Piezoelectric analysis is carried out with upper and lower pads completely constrained $(u, v, w=0)$ (Figure 13). By applying an equivalent voltage $(175 \mathrm{~V})$, the von Mises stress $(92 \mathrm{MPa})$ and the block force are computed $(81 \mathrm{~N})$, respectively. Further analysis is done for finding the induced displacement of the APA actuator under unconstrained 


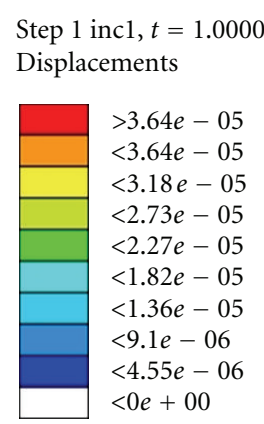

$\operatorname{Max}=4.09 e-05$

$\operatorname{Min}=0 e+00$

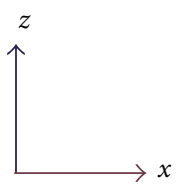

(a)

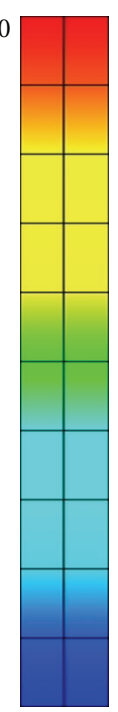

Step 1 incl, $t=1.000000 e+000$ Reaction forces

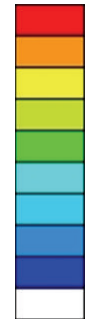

$>2.88 e+02$

$<2.88 e+02$

$<2.52 e+02$

$<2.16 e+02$

$<1.8 e+02$

$<1.44 e+02$

$<1.08 e+02$

$<7.19 e+01$

$<3.6 e+01$

$<0 e+00$

$\operatorname{Max}=3.24 e+02$

$\operatorname{Min}=0 e+00$

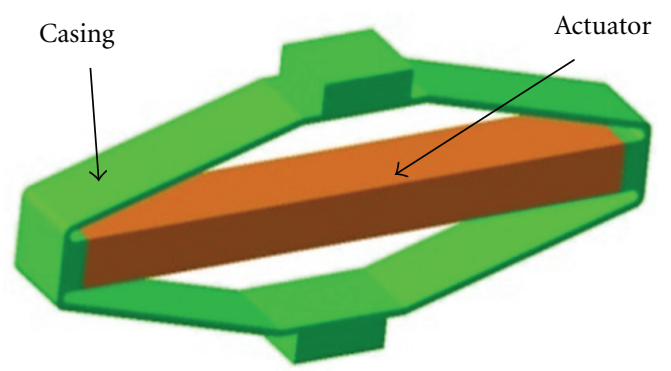

FIgURE 12: CAD model of the APA.

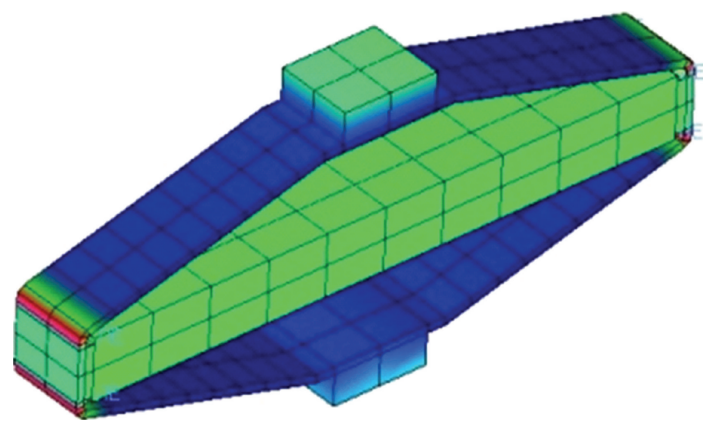

Figure 13: Pzeio static analysis APA actuator.

state $(148 \mu \mathrm{m})$. The result is presented in Figure 14 . Similarly for different actuator voltages, the free deflections are computed, at actuator level as well as for the APA. The results are presented in Table 5 for different voltage configurations.

\section{Conclusions}

A diamond-shaped APA was successfully fabricated by designing suitable metal frame and using 6 multilayered PZT stacks. The APA produces displacement of $173 \mu \mathrm{m}$ with 
Step 1 incl, $t=1.000000 e+000$

Displacements

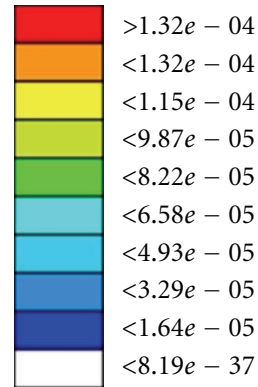

$\operatorname{Max}=1.48 e-04$

$\operatorname{Min}=8.19 e-37$

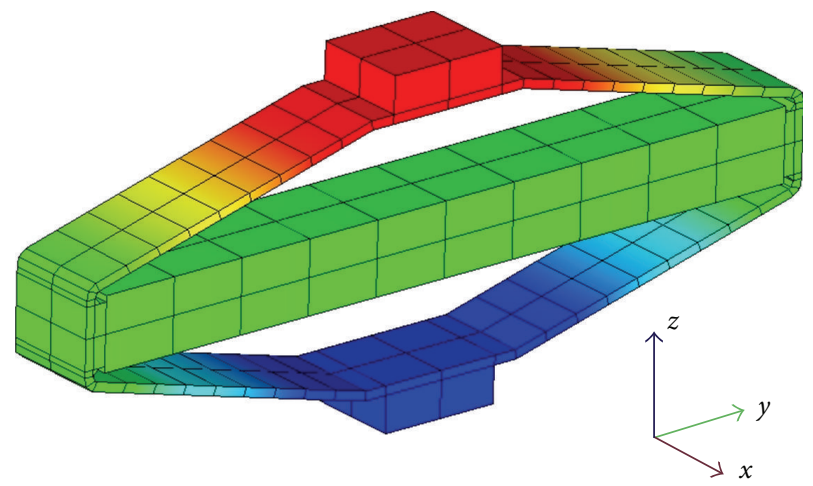

FIGURE 14: Electromechanical analysis of APA.
TABLE 5: Displacement values of APA.

\begin{tabular}{lccc}
\hline $\begin{array}{l}\text { Actuator } \\
\text { Voltage }(\mathrm{V})\end{array}$ & $\begin{array}{c}\text { Equivalent } \\
\text { numerical } \\
\text { voltage }(\mathrm{V})\end{array}$ & $\begin{array}{c}\text { ABAQUS-free } \\
\text { Displacement of } \\
\text { actuator } \\
(\Delta x) \mu \mathrm{m}\end{array}$ & $\begin{array}{c}\text { ABAQUS-APA } \\
\text { Displacement } \\
(\mu \mathrm{m})\end{array}$ \\
\hline 175 & 5250 & 40.9 & 148 \\
160 & 4800 & 37.4 & 135 \\
140 & 4200 & 32.8 & 118 \\
120 & 3600 & 28.1 & 102 \\
100 & 3000 & 23.4 & 84.6 \\
80 & 2400 & 18.7 & 67.7 \\
60 & 1800 & 14 & 50.8 \\
40 & 1200 & 9.38 & 33.8 \\
20 & 600 & 4.68 & 16.9 \\
0 & 0 & 0 & 0 \\
\hline
\end{tabular}

displacement amplification of 4.3 times. The actuator was subjected to different frequencies and different AC voltages. The performance was found very well over the frequency range without attenuation of the signal. Both the waveforms, namely, input to the stack actuator and accelerometer output, is showing no distortion thereby indicating the stack actuator assembly is behaving linearly. The equivalent numerical modeling of APA was built, and electromechanical analysis was carried out. The induced displacement obtained was $148 \mu \mathrm{m}$ for the maximum operational voltage. The actuator free displacement and block force were also computed to be $40.9 \mu \mathrm{m}$ and $1450 \mathrm{~N}$, respectively. The maximum vonMises stress estimated is $92 \mathrm{MPa}$, which gives a factor of safety of 4.7, and block force generated is $81 \mathrm{~N}$. The block force of the APA was $81 \mathrm{~N}$, calculated by electromechanical analysis. This is similar to that calculated by dynamic characterization method.

\section{Acknowledgments}

The authors gratefully acknowledge Mr. M. K. Sridhar, Head, Materials Science Division, and Dr. A. R. Upadhya, Director, NAL, for their encouragement and the support during the course of this study. The authors also thank Mr. Chandraiah, project assistant, for his help in preparation of PZT tapes.

\section{References}

[1] R. E. Newnham and G. R. Ruschau, "Smart electroceramics," American Ceramic Society Bulletin, vol. 75, no. 10, pp. 51-61, 1996.

[2] G. H. Haertling, "Rainbow ceramics-a new type of ultra-highdisplacement actuator," American Ceramic Society Bulletin, vol. 73, no. 1, pp. 93-98, 1994.

[3] R. E. Newnham and G. R. Ruschau, "Smart electroceramics," Journal of the American Ceramic Society, vol. 74, no. 3, pp. 463480, 1991.

[4] E. F. Crawley and J. De Luis, "Use of piezoelectric actuators as elements of intelligent structures," AIAA Journal, vol. 25, no. 10, pp. 1373-1385, 1987.

[5] K. Uchino, "Advances in ceramic actuator materials," Materials Letters, vol. 22, no. 1-2, pp. 1-4, 1995.

[6] J. Juuti, K. Kordás, R. Lonnakko, V. P. Moilanen, and S. Leppävuori, "Mechanically amplified large displacement piezoelectric actuators," Sensors and Actuators A, vol. 120, no. 1, pp. 225-231, 2005.

[7] C. Niezrecki, D. Brei, S. Balakrishnan, and A. Moskalik, "Piezoelectric actuation: state of the art," The Shock and Vibration Digest, vol. 33, no. 4, pp. 269-280, 2001.

[8] A. Dogan, Q. Xu, K. Onitsuka, S. Yoshikawa, K. Uchino, and R. E. Newnham, "High displacement ceramic metal composite actuators (moonies)," Ferroelectrics, vol. 156, no. 1, pp. 1-6, 1994.

[9] L. Denghua, F. Daining, W. Lina, J. Weijun, and J. Meijian, "Cymbal piezocomposites for vibration accelerometer applications," Integrated Ferroelectrics, vol. 78, no. 1, pp. 165-171, 2006. 
[10] M. Joshi and S. Priya, "Piezo-bow-high displacement and high blocking force actuator," Integrated Ferroelectrics, vol. 82, no. 1, pp. 25-43, 2006.

[11] H. Zhou and B. Henson, "Analysis of a diamond-shaped mechanical amplifier for a piezo actuator," International Journal of Advanced Manufacturing Technology, vol. 32, no. 1-2, pp. $1-7,2007$.

[12] B. Watson, J. Friend, and L. Yeo, "Piezoelectric ultrasonic micro/milli-scale actuators," Sensors and Actuators A, vol. 152, no. 2, pp. 219-233, 2009.

[13] X. Li, J. S. Vartuli, D. L. Milius, I. A. Aksay, W. Y. Shih, and W. H. Shih, "Electromechanical properties of a ceramic d," Journal of the American Ceramic Society, vol. 84, no. 5, pp. 9961003, 2001.

[14] Y. Sugawara, K. Onitsuka, S. Yoshikawa, Q. Xu, R. E. Newnhan, and K. Uchino, "Metal-ceramic composite actuators," Journal of the American Ceramic Society, vol. 75, no. 4, pp. 996-998, 1992.

[15] J. F. Fernández, A. Dogan, J. T. Fielding, K. Uchino, and R. E. Newnham, "Tailoring the performance of ceramic-metal piezocomposite actuators, "cymbals",' Sensors and Actuators A, vol. 65, no. 2-3, pp. 228-237, 1998.

[16] B. Sahoo, V. A. Jaleel, and P. K. Panda, "Development of PZT powders by wet chemical method and fabrication of multilayered stacks/actuators," Materials Science and Engineering B, vol. 126, no. 1, pp. 80-85, 2006. 

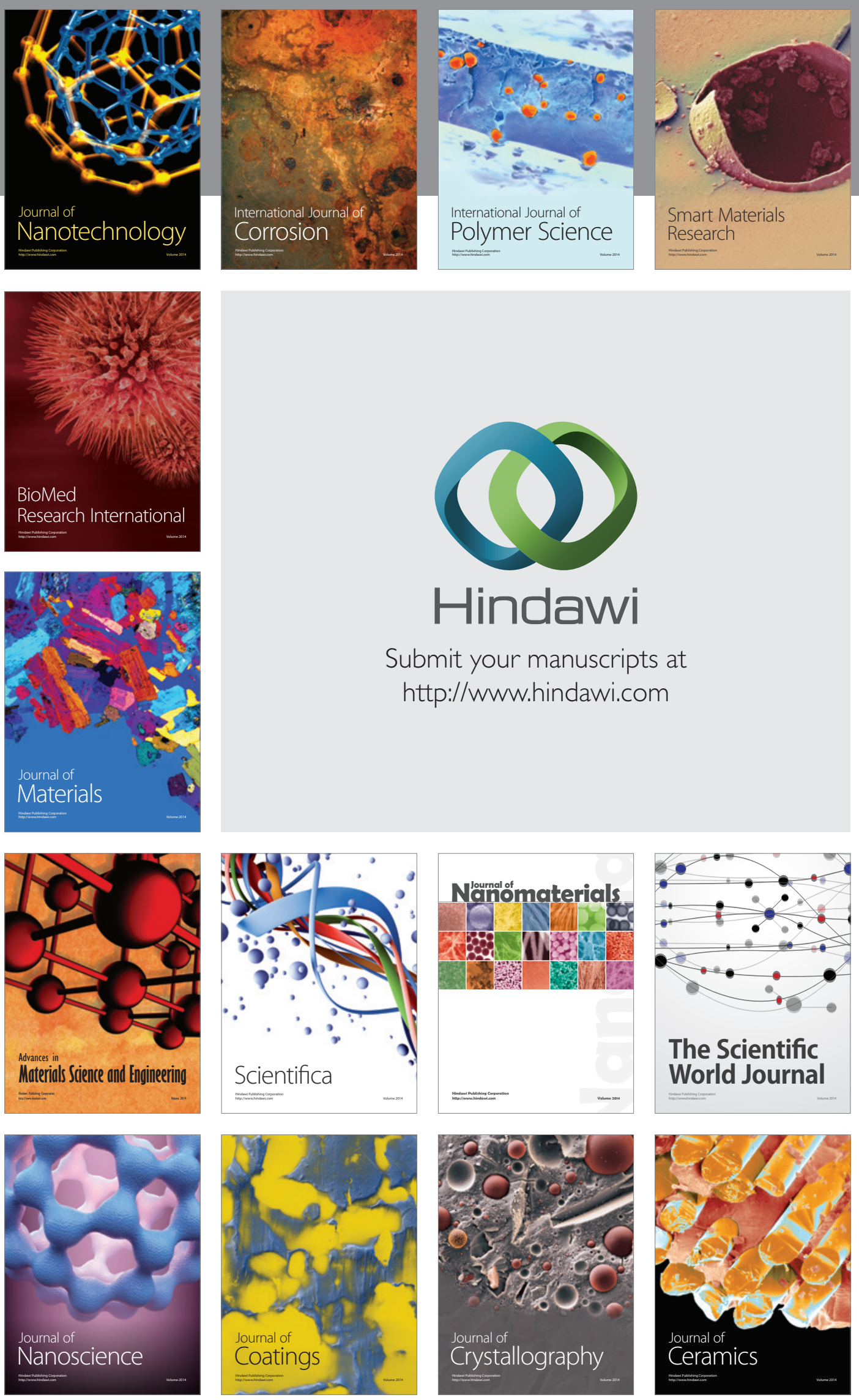

The Scientific World Journal

Submit your manuscripts at

http://www.hindawi.com

\section{World Journal}

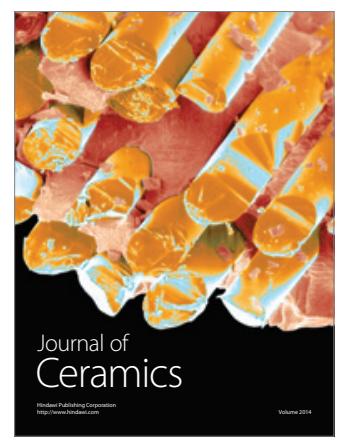

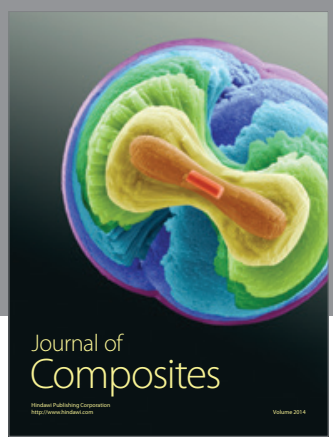
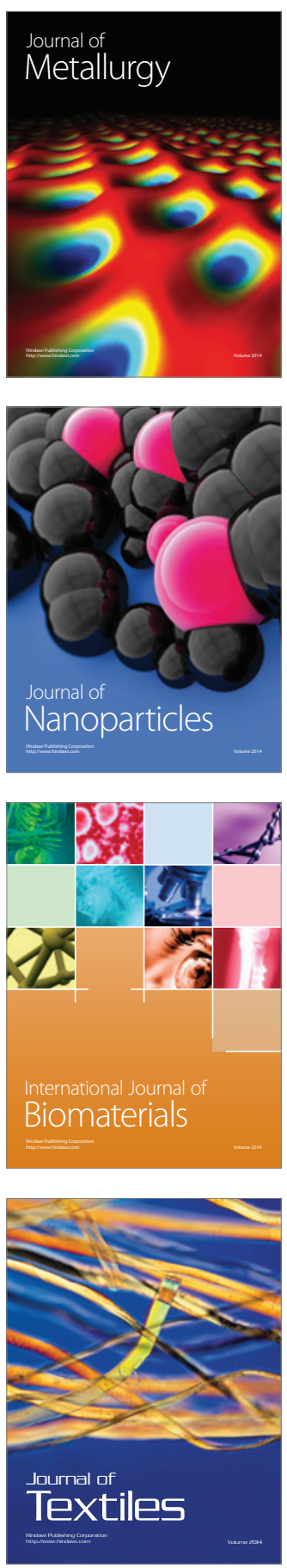